\title{
Correlation between an angiographic and a cardiac magnetic resonance score of myocardial jeopardy using standard and high-resolution perfusion sequences
}

\author{
Geraint Morton*, Masaki Ishida, Kalpa De Silva, Pierre Sicard, Amedeo Chiribiri, Andreas Schuster, Shazia Hussain, \\ Matthias Paul, Divaka Perera, Eike Nagel
}

From 2011 SCMR/Euro CMR Joint Scientific Sessions

Nice, France. 3-6 February 2011

\section{Objective}

Evaluate the correlation between a Cardiac Magnetic Resonance (CMR) and an angiographic myocardial jeopardy score in coronary artery disease (CAD) using either a high-resolution or a standard perfusion sequence.

\section{Background}

High temporal resolution required for CMR perfusion imaging results in compromised spatial resolution. However, recent advances, including the use of the advanced acceleration method $k$ - $t$ sensitivity encoding, allow myocardial perfusion imaging with unprecedented spatial resolution. The associated benefits remain to be fully described.

The BCIS-1 Myocardial Jeopardy Score (JS) quantifies the amount of myocardium in jeopardy from severe CAD ( $0=$ no jeopardy; 12 = maximum jeopardy). It accommodates patients with CABG and left main disease, is prognostically relevant and can easily be calculated by visual analysis of the X-ray coronary angiogram (XCA). Combined perfusion and scar CMR imaging should provide equivalent functional information on myocardial jeopardy. High-resolution perfusion imaging may improve the correlation between JS and CMR findings.

\section{Methods}

40 consecutive study patients with known or suspected CAD underwent 1.5T CMR imaging and standard

King's College London, London, UK

Full list of author information is available at the end of the article diagnostic XCA. CMR stress and rest perfusion imaging included 3 transverse slices every heartbeat using a standard TFE (st-TFE) sequence (17 patients) or a highresolution kt balanced Turbo Field Echo (kt-TFE) sequence (23 patients). Typical acquired spatial resolution: $2.8 \times 2.5 \times 10 \mathrm{~mm}$ and $1.7 \times 1.9 \times 10 \mathrm{~mm}$ respectively. Cine and scar imaging were also performed.

Data analysis was blind. CMR perfusion and scar data were segmented using the standard 17-segment model excluding the apex. Each segment was subdivided into equal endo and epicardial sub-segments. Sub-segments were assigned as $3 \%$ of the total myocardium each and classified as normal, ischaemia or scar. Percentage myocardium affected by ischaemia or scar was then calculated.

\section{Results (tables 1 and 2)}

There was a significant correlation between the JS and CMR score which was strongest in the high-resolution ktTFE group; $r=0.78, p=<0.0001$ and appeared less strong in the st-TFE group; $\mathrm{r}=0.63, \mathrm{p}=0.007$ (figures 1 and 2 ).

Table 1 st-TFE patient characteristics.

\begin{tabular}{ll}
\hline Age $($ mean \pm SD) & $64 \pm 8$ years \\
Coronary Artery Disease & $82 \%$ \\
Male & $71 \%$ \\
Hypertension & $82 \%$ \\
Diabetes & $41 \%$ \\
Previous CABG & $0 \%$ \\
Previous PCl & $6 \%$ \\
\hline
\end{tabular}


Table 2 kt-TFE patient characteristics

\begin{tabular}{ll}
\hline Age $($ mean \pm SD) & $67 \pm 11$ years \\
Coronary Artery Disease & $96 \%$ \\
Male & $78 \%$ \\
Hypertension & $61 \%$ \\
Diabetes & $35 \%$ \\
Previous CABG & $26 \%$ \\
Previous PCl & $26 \%$ \\
\hline
\end{tabular}

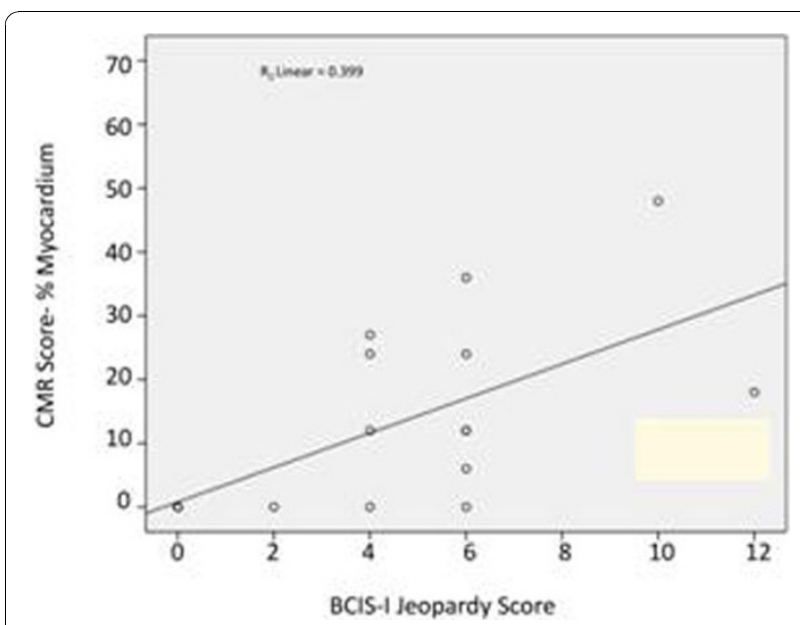

Figure 1 CMR Ischaemia/Scar Score versus JS st TFE perfusion cases

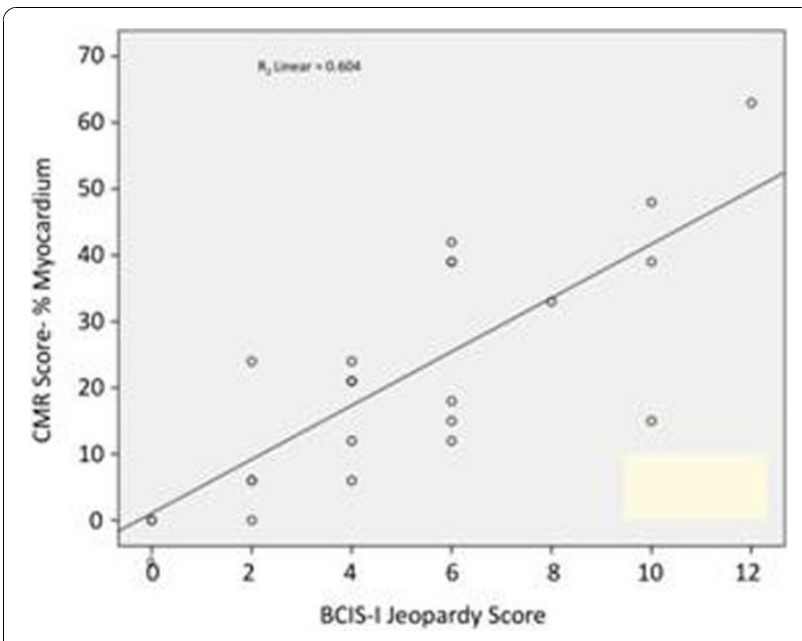

Figure 2 CMR Ischaemia/Scar Score versus JS kt TFE perfusion cases

\section{Conclusions}

There is a significant correlation between the anatomic JS and a functional CMR ischaemia/scar score. This correlation seems to improve with the use of a high-resolution perfusion technique. Complete correlation between the two scores would not be expected for reasons such as difficulty predicting the haemodynamic effects of anatomically moderate disease or post-revascularization when scar may be subtended by patent vessels. However, the correlation is likely to be clinically useful and using a high-resolution perfusion sequence may therefore be superior for imaging patients with CAD.

Published: 2 February 2011

doi:10.1186/1532-429X-13-S1-P89

Cite this article as: Morton et al: Correlation between an angiographic and a cardiac magnetic resonance score of myocardial jeopardy using

standard and high-resolution perfusion sequences. Journal of

Cardiovascular Magnetic Resonance 2011 13(Suppl 1):P89.
Submit your next manuscript to BioMed Central and take full advantage of:

- Convenient online submission

- Thorough peer review

- No space constraints or color figure charges

- Immediate publication on acceptance

- Inclusion in PubMed, CAS, Scopus and Google Scholar

- Research which is freely available for redistribution 